\title{
Reformas curriculares em cursos de licenciatura de Matemática: intenções necessárias e insuficientes
}

\section{Curriculum reforms in mathematics education programs for teachers: necessary and inadequate intentions}

\author{
Sonia Maria da Silva Junqueira ${ }^{1}$. Ana Lúcia Manrique ${ }^{2}$
}

\begin{abstract}
Resumo: Este artigo apresenta resultados de uma pesquisa que adotou uma abordagem interpretativa e descritiva, realizando uma análise documental no conjunto de documentos das Diretrizes Curriculares para os Cursos de Matemática. Ela foi revestida de uma perspectiva baumaniana, pois se entende que o movimento dos sólidos e dos líquidos, configurado por Bauman, propiciou uma averiguação de como esses documentos pretenderam dar novas formas aos cursos, e como os novos formatos podem ter sido compreendidos pelas instituições para, assim, investigar as permanências, ou seja, os "sólidos herdados" que se mantêm na formação dos professores de Matemática. Foi possível perceber as tentativas de derretimento de sólidos, observados nas várias reformas com a intenção de dar nova forma ao ensino. Destacaram-se as tentativas de dissolver certos sólidos, tais como: dissolver a dicotomia entre teoria e prática; a separação dos conteúdos específicos e pedagógicos, e a valorização do Bacharelado em detrimento da Licenciatura em Matemática.
\end{abstract}

Palavras-chave: Licenciatura em Matemática. Currículo. Modernidade líquida. Formação de professores.

\begin{abstract}
This article presents the results of research that adopted a descriptive and interpretive approach, by performing a desk review of documents in the set of Curriculum Guidelines for Mathematics courses. It was set within a Baumanian perspective, since it is understood that the movement of solids and liquids configured by Bauman led to an investigation of how these documents were intended to give new shape to the courses and how the new formats may have been understood by the institutions and to thereby investigate its permanence, namely the "legacy solids" which remain in the initial training of teachers of mathematics. It could be observed that there were attempts to melt this solid, in several reforms intended to reshape education. The highlights were the attempts to dissolve some solids, such as dissolving the dichotomy between theory and practice; separation of specific and pedagogical content and the appreciation of the Bachelor degree to the detriment of the Teacher Education of Mathematics.
\end{abstract}

Keywords: Teacher education of Mathematics. Curriculum. Liquid modernity. Teacher education.

\footnotetext{
${ }^{1}$ Universidade Federal do Pampa (UNIPAMPA), Travessa quarenta e cinco (Malafaia), 1.650, CEP 96413-170, Bagé, RS, Brasil. E-mail: <soniajunqueira@unipampa.edu.br>

${ }^{2}$ Departamento de Matemática, Centro de Ciências Matemáticas Físicas e Tecnológicas, Pontifícia Universidade Católica de São Paulo (PUC-SP), São Paulo, SP, Brasil.
} 


\section{Introdução}

O debate sobre a constituição da identidade de cursos de Licenciatura em Matemática e de aspectos que envolvem a formação do futuro professor de Matemática ocupa considerável espaço de discussão nos meios acadêmicos em nosso país. Acrescenta-se, ainda, a importância dada à pesquisa dos processos de formação de professores que, além de recente no Brasil, como em outros países, também precisam de estudos voltados ao Ensino Superior, sobretudo no que se refere ao processo de formação inicial do professor. Assim, apresenta-se, neste artigo, uma reflexão sobre as reformas curriculares nos cursos de Licenciatura em Matemática, tendo em vista esta discussão.

Para perseguir o objetivo deste trabalho, procede-se a uma caracterização temporal justificada pelo fato de que o sujeito em formação está situado no presente real, em que é constituído, e também o projeto de ações das instituições formadoras. Desta forma, ressaltam-se aspectos que se "solidificaram" ou se encontram "liquefeitos", para tomar "novas", ou, talvez, "melhores" formas no sentido anunciado por Bauman $(2001,2005)$, cuja modernidade líquida se refere à época atual, ao conjunto de relações e instituições, além de sua lógica de operações, que se impõe e sustenta a contemporaneidade. Desse modo, configura-se a época da liquidez, de fluidez, de volatilidade, da incerteza e insegurança, em que toda a fixidez e todos os referenciais morais da modernidade sólida são substituídos a fim de darem espaço à lógica do agora, do consumo, da artificialidade, da fluidez.

Entende-se que este trabalho está fundamentado na perspectiva de uma pesquisa qualitativa, por meio da qual se pretende defender suposições que admitam, aos indivíduos, a capacidade de procurar entender o mundo em que vivem, desenvolvendo significados subjetivos de suas experiências. Diante desses significados, ao contrário de estreitar um ponto de vista, muitas vezes, se é levado a buscar a complexidade.

Assim, por meio de uma abordagem interpretativa e descritiva, realizou-se uma análise documental no conjunto de documentos das Diretrizes Curriculares para os Cursos de Matemática, que propiciaram uma averiguação de como esses documentos pretenderam dar novas formas aos cursos de Licenciatura em Matemática, e como os novos formatos podem ter sido compreendidos pelas entidades formadoras, para, assim, investigar as permanências, ou seja, os "sólidos herdados" que se mantêm na formação dos professores de Matemática, mesmo após mudanças ocorridas por imposições legais, ou não, no cenário político educacional.

\section{Fluidez e decorrentes solidificações asseguradas por reformas legais}

Torna-se necessário apresentar o entendimento sobre a caracterização dada por Bauman a expressões como modernidade líquida e derretimento de sólidos. O sentido apontado por Bauman (2001) revela uma realidade na qual, incessantemente, se detém em tentar tornar mais lento o fluxo e a dar forma ao disforme - este é o cenário das transformações no qual esse autor assenta a metáfora da modernidade líquida. Assim, modernidade líquida designa o estado atual em que tudo está submetido a uma constante remodelação, compreensão que se pode ter em todos os aspectos da vida humana e de suas adaptações. Nesse sentido, colocam-se também as transformações e pretensões de novas formas aos cursos de formação de profes- 
sores de Matemática no Brasil, um processo contínuo de tentativas de remodelação, contudo, ainda inconsistentes.

Bauman (2001) fala que, na modernidade líquida, "tudo" está sempre pronto a ser colocado em "processo de derretimento" - as famílias, as formas de trabalho, as formas de consumo, as crenças e a identidade. As formas em toda a sua variedade, na modernidade líquida, embora tentem permanecer e resistir ao tempo, estão submetidas a um movimento de remodelação contínua.

Derretimento de sólidos é empregado para indicar a desintegração dos discursos sólidos, em vias de enferrujamento dos compostos institucionalizados.

$\mathrm{Na}$ verdade, nenhum molde foi quebrado sem que fosse substituído por outro; [...] A tarefa dos indivíduos era usar sua nova liberdade para encontrar o nicho apropriado e ali se acomodar e adaptar: seguindo fielmente as regras e modos de conduta identificados como corretos e apropriados para aquele lugar. (BAUMAN, 2001, p. 13)

E expressa, ainda, que a modernidade não foi um processo de liquefação desde o começo, nem o derretimento dos sólidos seu maior passatempo e principal realização. A era da modernidade líquida, conforme apresenta Bauman (2001), se traduz em formas que se desfazem e se refazem diante das inseguranças e incertezas deste cenário.

Pois, a Modernidade Líquida traduz uma época em que, por exemplo, as relações de trabalho estão cada vez mais desgastadas em relação à própria esfera do trabalho, constituindose um campo fluido e desregulamentado, fazendo emergir um espaço de volatilidade crônica. Conexão é outro termo importante, pois é usado para descrever as frágeis relações pessoais. A vantagem não é referida nas várias conexões realizadas, mas na capacidade de desconexão sem maiores perdas ou custos. Assim, expõe a fragilidade do sujeito líquido, em que toda a autoridade de referência é colocada em si e em sua capacidade de escolher normas a serem seguidas. Como uma questão de escolher a melhor opção, ou as melhores vantagens, e, consequentemente, com a menor ou nenhuma desvantagem.

Dessa perspectiva, apresenta-se a análise de documentos referentes à primeira Lei de Diretrizes e Bases da Educação Nacional e seus reflexos nos cursos de Licenciatura em Matemática.

A Lei no 4.024, de 20 de dezembro de 1961, primeira Lei de Diretrizes e Bases da Educação Nacional (LDBEN) (BRASIL, 1961), trouxe, em seu bojo, um primeiro modelo federativo de administração da educação brasileira. Ao criar o Conselho Federal de Educação (CFE), delegou-lhe, entre outras competências, a fixação dos conteúdos mínimos e a duração dos cursos Superiores para a formação de pessoal para profissões regulamentadas em lei, entre elas, a Licenciatura em Matemática.

Pelas mudanças promovidas por essa Lei, a Licenciatura passou a ser considerada como um curso único de quatro anos. Nesse novo formato, a formação pedagógica poderia ocorrer simultaneamente a outras disciplinas acadêmicas. É o fim da obrigatoriedade de fazer um curso de Bacharelado e uma formação complementar para a Licenciatura; os dois cursos, agora, passam a ser independentes.

Segundo Ziccardi (2009), no Parecer 295, aprovado em 14 de novembro de 1962, consta que o currículo mínimo para a Licenciatura em Matemática deveria ser ministrado em um único 
curso de quatro anos de duração, que abrangeria as seguintes matérias: Desenho Geométrico e Geometria Descritiva, Fundamentos da Matemática Elementar, Física Geral, Cálculo Diferencial e Integral, Geometria Analítica, Álgebra e Cálculo Numérico. Para a matéria Fundamentos da Matemática Elementar é sugerida uma análise e revisão dos assuntos lecionados nos, então, cursos ginasial e colegial, tendo em vista o aprofundamento desses assuntos.

Esse Parecer considerou a necessidade de familiarização do licenciando com o aluno e métodos de ensino da Escola Básica, recomendando que as disciplinas de formação pedagógica passassem a ser distribuídas ao longo do curso. No entanto, a carga horária das disciplinas de formação pedagógica foi reduzida de $1 / 4$ para $1 / 8$ da carga horária total do curso, além do fato de, na maior parte dos casos, serem ministradas em unidades universitárias separadas. Essa dinâmica provocou um distanciamento ainda maior entre as disciplinas da Ciência de Referência, ofertadas pelos institutos, e as disciplinas das Ciências da Educação, com vistas à formação do futuro professor, ofertadas nas faculdades de Educação.

O Parecer no 295/62 (BRASIL, 1962) propunha, para os cursos de formação de professores, as seguintes disciplinas de formação pedagógica obrigatórias: Psicologia da Educação (adolescência e aprendizagem), Didática e Elementos da Administração Escolar e Prática de Ensino na matéria de habilitação (sob a forma de estágio supervisionado).

A Reforma Universitária de 1968, Lei no 5.540/68 (BRASIL, 1968), teve a finalidade de apresentar mecanismos de mudanças, já que a universidade se expandiu, mas, em seu cerne, permaneceu com a mesma estrutura anacrônica, como um entrave ao processo de desenvolvimento.

Nessa época, o Ensino Superior quase triplicou seu efetivo em relação à década precedente, apresentando um elenco de meia centena de cursos que conferiam privilégios profissionais. Segundo Sucupira (1972), a universidade brasileira se resumia a um vasto aglomerado de faculdades, institutos e serviços. Dessa forma, a reforma apresentou um sentido instaurativo. Contudo, a universidade brasileira não obedeceria ao planejamento racional, nem determinaria a reorganização de seus quadros estruturais e de seus métodos de ensino.

Nesse movimento, Sucupira (1972) reconhece que o crescimento desenfreado das universidades se fez por simples multiplicação de unidades, em vez de desdobramentos orgânicos; houve acréscimo de novos campos e atividades que foram progressivamente anexados. Esse autor ainda acrescenta que o crescimento não foi apenas vegetativo, e também não chegou a ser um desenvolvimento orgânico, o que implicaria mudança qualitativa e reorganização dinâmica, não apenas justaposição de partes.

Como consequência, ocorreu: a inevitável fragmentação do trabalho docente, o isolamento de pesquisadores e a dispersão de alunos pelo sistema de créditos. Para o licenciando em Matemática, por exemplo, a preparação dada, na época, possibilitava ministrar aulas de Matemática, Física, Desenho e/ou Ciências, nos ensinos de $1^{\circ}$ e $2^{\circ}$ graus, equivalentes ao atual Ensino Fundamental e Ensino Médio, respectivamente, caso tais disciplinas fossem contempladas em seu currículo de sua formação.

As modificações decorrentes das ações implementadas pela Lei causaram transformações nas universidades brasileiras, inclusive, na qualidade de ensino. Para Ghiraldelli Jr. (2009), as modificações reforçaram ainda mais a dicotomia "específico versus pedagógico", já presente nos cursos de formação de professores na época, haja vista a departamentalização e os profissionais agrupados por áreas comuns do conhecimento. Com a desarticulação entre as 
interações por afinidades teóricas e ideológicas, se instauraram aglomerações corporativistas, extremamente prejudiciais ao ensino e à pesquisa.

Além disso, a separação locus temporal entre os polos de formação específico e pedagógico, que aparece desde a criação dos cursos de Licenciatura na década de 1930 - época em que os cursos de Licenciatura eram vistos como parte da função "menos nobre" da universidade vai se consolidando, sobretudo, em função dos objetivos e funções assumidas pela comunidade acadêmica envolvida e as políticas públicas para o Ensino Superior no país.

Com a Reforma Universitária implantada a partir de 1968, não se conseguiu dissolver a tradição de escolas isoladas e profissionalizantes, características do Ensino Superior brasileiro desde suas origens. Conforme afirma Ghiraldelli Jr (2009), os cursos de formação de professores foram seriamente comprometidos por esta lógica marcada por dicotomias, preservando, justamente, a forma que se pretendia dissolver.

Nessa direção, o caminho percorrido pela legislação que prevê os fundamentos e normatização do sistema educacional brasileiro percorreu longos anos desde o surgimento da primeira lei até sua regulamentação final. A primeira LDB, Lei no 4.024/61 (BRASIL, 1961), foi debatida por cerca de 13 anos até sua promulgação. Fundamentadas em ideais desenvolvimentistas, as emendas que ajustaram o texto regulamentar da Lei 4.024/61 contribuíram para que fosse sancionada a Lei 5.540/68 (BRASIL, 1968), que, por reformar a estrutura do ensino superior, ficou conhecida como lei da reforma universitária. Em 1971, uma nova lei para a educação brasileira foi apresentada, em pleno regime militar: a Lei 5.692/71 (BRASIL, 1971), que posteriormente foi substituída pela mais recente LDB, a Lei 9.394/96 (BRASIL, 1996). Nesse sentido, muito possivelmente, tenham sido palcos de divergências e embates, ou seja, a tentativa de progresso em diretrizes que buscaram regulamentar a educação no país constitui tentativas de "derretimento de sólidos", se pensarmos no sentido de Bauman (2001).

Assim, a Lei n ${ }^{\circ}$ 9.394/96 (LDBEN), ancorada num espírito de maior flexibilidade para a organização dos cursos na educação, entendeu como extemporâneos os currículos mínimos e sua excessiva rigidez, e que, por essa razão, certamente atrapalhariam as instituições na busca de inovações e diversificações em suas propostas curriculares.

A ideia de deliberar sobre diretrizes curriculares para os cursos de graduação foi regulamentada com a aprovação da LDBEN de 1996. Estabeleceu-se, assim, como um dos deveres das universidades: a fixação dos currículos de seus cursos e programas, conforme orientação das diretrizes gerais pertinentes.

A partir dessa Lei, a avaliação da Educação Superior assumiu um lugar de destaque entre as políticas educacionais, tanto como norteadora das diretrizes do Ministério da Educação (MEC), como na orientação de suas ações concretas.

Admite-se, assim, que as Instituições de Ensino Superior estejam se remodelando, ou seja, estejam em pleno processo de conformação com os mecanismos de mudanças, tomando, para si, os novos contornos por ora exigidos e, desse modo, criando novas estruturas e remodelando suas formas internas.

Pode-se considerar, conforme Bauman (2001), que essas instituições estejam passando, então, por um constante processo de tentativa de liquefação. Resta descobrir se a fase atual de liquefação será capaz de dissolver sólidos, ou seja, dissolver aspectos consolidados e que permanecem inalterados no interior das instituições. 


\section{Diretrizes Curriculares Nacionais e o movimento na formação de professores}

Setores representativos da sociedade, na qual se sustenta a modernidade líquida de Bauman (2001), ao mesmo tempo em que se inserem na reconstrução de novas necessidades e expectativas, apresentam um instrumento de caráter modelador.

Evidências, a partir de pesquisas educacionais, apontam para uma pseudodemocracia, como se encontra em Marques e Diniz Pereira (2002), ao discorrerem sobre a adoção de políticas educacionais que buscam, ao contrário de inovação nos cursos de Licenciatura, prioritariamente, $\mathrm{o}$ atendimento de organismos internacionais que regulam o sistema capitalista.

Assim, as Diretrizes Curriculares Nacionais para a Formação de Professores da Educação Básica apresentam um conjunto de princípios, fundamentos e procedimentos a serem observados na organização institucional e curricular de cada estabelecimento de Ensino Superior. A organização curricular a que se refere o Parecer CNE/CP 009/2001 deve observar as competências inerentes à formação para a atividade docente, entre as quais:
I - o ensino visando à aprendizagem do aluno;
II - o acolhimento e o trato da diversidade;
III - o exercício de atividades de enriquecimento cultural;
IV - o aprimoramento em práticas investigativas;
$\mathrm{V}$ - a elaboração e a execução de projetos de desenvolvimento dos conteúdos curriculares;
VI - o uso de tecnologias da informação e da comunicação e de meto- dologias, estratégias e materiais de apoio inovadores;
VII - o desenvolvimento de hábitos de colaboração e de trabalho em equipe. (BRASIL, 2002b, p. 61)

Porém, as orientações, como se apresentam, contribuem para interpretações diversas e não representam, necessariamente, que as competências esperadas sejam desenvolvidas a partir das novas estruturas dos cursos de formação de professores.

O Parecer $n^{\circ}$ 09/2001 (BRASIL, 2002b) apresenta, entre as inúmeras dificuldades encontradas para a implantação dessa proposta, que envolve o desenvolvimento de competências, "o preparo inadequado dos professores cuja formação de modo geral, manteve predominantemente um formato tradicional", que, segundo o relatório, não "contempla muitas das características consideradas, na atualidade, como inerentes à atividade docente" (BRASIL, 2002b, p. 4).

A partir do Parecer CNE/CP 009/2001, são considerados fundamentais para o desenvolvimento dos cursos de Licenciatura: o conjunto das competências necessárias à atuação profissional, assim como, a adoção dessas competências como norteadoras, tanto da proposta pedagógica, em especial do currículo e da avaliação, quanto da organização institucional e da gestão da escola de formação. No entanto, é difícil constatar e reconhecer esses elementos nos projetos pedagógicos dos cursos de Licenciatura (GATTI; NUNES, 2008).

O projeto pedagógico de um curso de Licenciatura, segundo as Diretrizes Curriculares Nacionais para os Cursos de Formação de Professores, deverá levar em conta que: a forma- 
ção esperada deva garantir a constituição das competências objetivadas na Educação Básica; o desenvolvimento das competências exija que a formação contemple diferentes âmbitos do conhecimento profissional do professor; a seleção dos conteúdos das áreas de ensino da Educação Básica oriente-se para além do que os professores irão ensinar nas diferentes etapas da escolaridade; os conteúdos a serem ensinados na escolaridade básica devam ser tratados de modo articulado com suas didáticas específicas; a avaliação tenha, como finalidade: a orientação do trabalho dos formadores, a autonomia dos futuros professores em relação ao seu processo de aprendizagem e a qualificação dos profissionais aptos a iniciarem a carreira.

Ainda, segundo as Diretrizes Curriculares para os Cursos de Formação de Professores, na construção do projeto pedagógico, deverão ser consideradas as competências referentes: ao comprometimento com os valores inspiradores da sociedade democrática; à compreensão do papel social da escola; ao domínio dos conteúdos a serem socializados, aos seus significados em diferentes contextos e sua articulação interdisciplinar; ao domínio do conhecimento pedagógico; ao conhecimento de processos de investigação que possibilitem o aperfeiçoamento da prática pedagógica, e ao gerenciamento do próprio desenvolvimento profissional.

Assim, tem seu lugar a complexidade estabelecida no modelo de formação, segundo as orientações apontadas por essas Diretrizes, complexidade que, também, exige reflexão:

Hoje, os padrões e configurações não são mais “dados", e menos ainda "auto-evidentes", eles são muitos, chocando-se entre si e contradizendose em seus comandos conflitantes, de tal forma que todos e cada um foram desprovidos de boa parte de seus poderes de coercitivamente compelir e restringir. (BAUMAN, 2001, p. 14)

Hargreaves (2004) também retrata essa complexidade ao descrever a inserção dos professores em uma sociedade em constante mudança. Para esse autor, é a sociedade contemporânea o lugar onde os professores devem desenvolver capacidades para conduzir investigações, quando confrontados com novas demandas e problemas. São esses professores, nesse sentido, catalisadores da sociedade, que deve ter a responsabilidade de formar o sujeito global com as habilidades e competências que lhes são requeridas.

[...] os professores precisam tentar transformar as escolas em organizações de aprendizagens onde a capacidade de aprender tem a preocupação com a aprendizagem cognitiva, trabalho em grupo, auto-monitoramento profissional, uso inovador da tecnologia, informação, dados, pesquisa, resolução de problemas, assumir riscos, mudar e melhorar continuamente. (HARGREAVES, 2004, p. 8)

As Diretrizes apontam a flexibilidade como o modo de cada instituição formadora construir projetos próprios e inovadores, de forma a integrar os eixos articuladores das dimensões teóricas e práticas. Nesse aspecto, a possibilidade de variados formatos de cursos é permitida. Para Bauman (2001), um projeto requer muito mais que projetos individuais, mas um trabalho coletivo, e, nesse sentido, afirma que: 
Os sólidos que estão para ser lançados no cadinho e os que estão derretendo neste momento, o momento da modernidade fluida, são os elos que entrelaçam as escolhas individuais em projetos e ações coletivas - os padrões de comunicação e coordenação entre as políticas da vida conduzidas individualmente, de um lado, e as ações políticas de coletividades humanas, de outro. (BAUMAN, 2001, p. 12)

O Parecer CNE/CP 009/2001 afirma, ainda, que os programas de formação de professores no Brasil mantêm um caráter que, predominantemente, preserva o formato $3+1$, inspirado no modelo da racionalidade técnica. Essa condição é uma das principais dificuldades apontadas para a implementação de mudanças na educação, mudanças essas, necessárias e condizentes com as atuais transformações sociais, políticas e econômicas (BRASIL, 2002b).

É possível observar, como uma finalidade das Diretrizes, que a Licenciatura passe a ter terminalidade e integralidade próprias, constituindo-se num projeto específico. Para isso, são necessárias as definições de currículos próprios para as Licenciaturas, que não preservem a antiga formação 3+1. No entanto, historicamente, as Licenciaturas constituíram-se nesse formato, em que as disciplinas da ciência de referência eram ministradas nos três primeiros anos do curso, ficando as disciplinas de cunho pedagógico justapostas ao final desse período, no último ano do curso.

Desse modo, entende-se que as orientações propostas e estruturadas pelas Diretrizes Curriculares para Formação de Professores possam apresentar características moderno líquidas, pois sólidos, como, por exemplo, a concepção da racionalidade técnica, contidos na estrutura de cursos de Licenciatura, nesse embate, podem ser contornados, inundados e até dissolvidos. Os líquidos, "do encontro com os sólidos emergem intactos, enquanto os sólidos que encontraram, se permanecem sólidos, são alterados - ficam molhados ou encharcados” (BAUMAN, 2001, p.8).

As Diretrizes apontam para a intenção de liquefazer essa forma e torná-la mais próxima do modelo da racionalidade prática, um modelo no qual o professor reflete, toma decisões, cria e recria sua prática pedagógica, que é entendida como um fenômeno complexo, singular, instável, carregado de incertezas e conflitos.

No entanto, uma distinção entre liberdade subjetiva e objetiva pode ser uma das justificativas pela qual se tende a permanecer num determinado estágio em que não se concebem mudanças.

Uma dessas questões é a possibilidade de que o que se sente como liberdade não seja de fato liberdade; que as pessoas poderem estar satisfeitas com o que lhes cabe mesmo que o que lhes cabe esteja longe de ser "objetivamente" satisfatório; [...] e, portanto, não experimentem a necessidade de se libertar, e assim percam a chance de se tornar genuinamente livres. (BAUMAN, 2001, p. 24-25) 


\section{Diretrizes Curriculares Nacionais para os Cursos de Matemática e a continuidade do movimento}

Recorreu-se à análise das Diretrizes Curriculares Nacionais para os Cursos de Matemática (Parecer CNE/CP 1.302/2001), com a finalidade de refletir sobre a constituição da identidade desses cursos (BRASIL, 2002a).

Há indícios de que os Cursos de Licenciatura em Matemática das universidades brasileiras sigam, de maneira geral, o modelo firmado na racionalidade técnica, apresentando uma estrutura curricular em que as disciplinas dos conteúdos específicos são ministradas antes das disciplinas pedagógicas. Porém, mudanças nessa estrutura são pretendidas e percebidas, num primeiro momento, por uma mobilidade social, em seguida, pelas manifestações legais.

No entanto, nesse redesenhar de formas, se evidencia como as Diretrizes Curriculares para os Cursos de Matemática podem se transformar em objeto de inovação. Mas, em contrapartida, podem também permitir interpretações distintas pelas instituições formadoras, admitindo que mecanismos propostos para inovação venham a se transformar em mecanismos que deformam a real e necessária mudança.

As Diretrizes Curriculares para os Cursos de Matemática, de modo conciso, estabelecem distinção entre os cursos de Bacharelado e Licenciatura, o que pode significar um dos sólidos mais remotos, a desvalorização das Licenciaturas. Em continuidade, orientam que os cursos de Bacharelado em Matemática devem preparar os futuros profissionais para a carreira de Ensino Superior e pesquisa, enquanto, para os cursos de Licenciatura em Matemática, o objetivo principal deve ser a formação de professores para a Educação Básica, o que o documento caracteriza como educador matemático (BRASIL, 2002a).

As Diretrizes Curriculares para os Cursos de Matemática, conforme Parecer CNE/CP 1.302/2001 (BRASIL, 2002a), apresentam as competências e habilidades adquiridas na formação do futuro profissional da Matemática.

As aplicações da Matemática têm se expandido nas décadas mais recentes. [...] As habilidades e competências adquiridas ao longo da formação do matemático tais como o raciocínio lógico, a postura crítica e a capacidade de resolver problemas, fazem do mesmo um profissional capaz de ocupar posições no mercado de trabalho também fora do ambiente acadêmico, em áreas em que o raciocínio abstrato é uma ferramenta indispensável. (BRASIL, 2002a, p. 1)

Dessa forma, as Diretrizes Curriculares para os Cursos de Matemática (BRASIL, 2002a) admitem que os programas de graduação devam ser flexíveis para acomodar o amplo campo de interesses do estudante, que, em geral, espera atuar nas mais diversas áreas correlatas ao seu campo de saber específico. Ainda consideram como inerentes ao processo de formação do matemático, tanto aspectos relativos à consolidação de conhecimentos e conceitos matemáticos adquiridos durante o Ensino Básico, quanto ao aprofundamento da compreensão dos significados do que deve ser desenvolvido no Ensino Superior, quando, então, o aluno já possui uma vivência e conjunto de representações adquiridas. 
E sugerem, conforme Parecer CNE/CP 1.302/2001 (BRASIL, 2002a), que os conteúdos curriculares dos cursos de Matemática sejam estruturados de modo a contemplarem, em sua composição, as seguintes orientações:

a) partir das representações que os alunos possuem dos conceitos matemáticos e dos processos escolares para organizar o desenvolvimento das abordagens durante o curso;

b) construir uma visão global dos conteúdos de maneira teoricamente significativa para o aluno (BRASIL, 2002a, p. 4).

De acordo com as Diretrizes (BRASIL, 2002a), os currículos devem assegurar o desenvolvimento de conteúdos dos diferentes âmbitos do conhecimento profissional de um matemático, levando-se em consideração as orientações apresentadas para a estruturação do curso.

A organização dos currículos das Instituições de Ensino Superior deve contemplar os conteúdos comuns aos cursos de Matemática, complementados com disciplinas organizadas conforme o perfil escolhido do aluno, admitindo-se a distribuição ao longo do curso de acordo com o currículo proposto pela própria instituição.

Os perfis do Bacharel e do Licenciado em Matemática configuram importante aspecto a ser analisado, pois o delineamento desses perfis revela a presença de sólidos e a intenção de possíveis derretimentos que parecem distantes de serem alcançados.

Nessa direção, verifica-se que o perfil esperado para o Bacharelado de Matemática é de um profissional com uma consistente base dos conteúdos de Matemática e uma formação que lhe prepare para enfrentar os desafios das rápidas transformações da sociedade, do mercado de trabalho e das condições de exercício profissional. Por outro lado, para os cursos de Licenciatura em Matemática, observa-se que o licenciando deve ter: a visão de seu papel social de educador e a capacidade de se inserir em diversas realidades com sensibilidade para interpretar as ações dos educandos; a visão da contribuição que a aprendizagem da Matemática pode oferecer à formação dos indivíduos para o exercício de sua cidadania; a visão de que o conhecimento matemático pode e deve ser acessível a todos, e consciência de seu papel na superação dos preconceitos, traduzidos pela angústia, inércia ou rejeição, que, muitas vezes, ainda estão presentes no ensino-aprendizagem da disciplina. Por esse posicionamento, pode-se admitir a especificidade na constituição da identidade do Bacharel em Matemática, e a complexidade da generalização evidente na constituição profissional do licenciado. Nesse sentido, há de se admitir que a intenção de dar uma especificidade à Licenciatura em Matemática parece ainda no cadinho.

Como componentes de inclusão à parte comum das Licenciaturas, essas Diretrizes sugerem: os conteúdos matemáticos presentes na Educação Básica nas áreas de Álgebra, Geometria e Análise; os conteúdos de áreas afins à Matemática, que são fontes de problemas e campos de aplicação de suas teorias; os conteúdos da Ciência da Educação, da História e Filosofia das Ciências e da Matemática, e as Tecnologias para o ensino da Matemática. 
Verifica-se, também, que os conteúdos, da forma como são apresentados nos cursos de Licenciatura em Matemática, não sugerem a construção de uma visão global de maneira significativa para o aluno, estão fragmentados, desvinculados de significados. Nesse sentido, o documento é contraditório.

Questiona-se se é possível preparar para uma carreira na qual a Matemática seja utilizada de modo essencial, assim como para um processo contínuo de aprendizagem, sem que haja uma consistente conceituação matemática. Da mesma forma, se somente ter uma consistente formação em conteúdos matemáticos basta para preparar para as rápidas transformações da sociedade, do mercado de trabalho e das condições de exercício profissional.

\section{Conclusão}

Por meio deste estudo, foram encontrados aspectos que parecem solidificados e que teimam em permanecer como fortes elementos na constituição da identidade de Cursos de Licenciatura em Matemática, mesmo após o impacto das atuais reformas e mudanças ocorridas no mundo contemporâneo. A modernidade líquida de Bauman (2001) se estabeleceu como o cenário para reconhecimento dos aspectos investigados.

Os constantes movimentos de tensão, ou seja, tentativas de derretimento de sólidos, observados nas várias reformas ocorridas por motivos essencialmente políticos, culturais e econômicos, com a intenção de dar nova forma ao ensino, foram percebidos. As várias reformas implementadas refletem a força desses movimentos, cada um influenciado por uma modernidade distinta.

Assim, configuram-se algumas tentativas de derretimento de sólidos: as propostas de modelos de formação docente implantadas; as demandas para a formação profissional resultantes das mudanças na Educação Básica brasileira; o lócus da preparação de professores e o processo de construção das Diretrizes Curriculares para as Licenciaturas. Nesse sentido, poderíamos admitir que alguns desses sólidos provavelmente tenham sido completamente dissolvidos, enquanto outros se encontram em processo de derretimento, e outros, ainda, talvez já tenham sido totalmente remodelados.

Especificamente, por meio do estudo das Diretrizes Curriculares Nacionais para os cursos de Matemática (BRASIL, 2002a), identificou-se a reincidência de quase a totalidade dos problemas apontados pelos diversos momentos de discussões. Identificou-se, também, como, por meio desse documento, se procurou apontar formas orientadoras para o redesenho dos cursos de Licenciatura em Matemática.

As tentativas de dissolver certos sólidos, em alguns momentos, pareceram impossíveis, tais como: dissolver a dicotomia entre teoria e prática; a separação dos conteúdos específicos e pedagógicos, e a valorização do Bacharelado em detrimento da Licenciatura em Matemática.

Da mesma forma, tem-se a convicção de que a remodelação de alguns desses sólidos pode não significar, necessariamente, o encontro de uma melhor configuração. 


\section{Referências}

BAUMAN, Z. Identidade. Rio de Janeiro: Jorge Zahar, 2005.

. Modernidade líquida. Rio de Janeiro: Jorge Zahar, 2001.

BRASIL. Lei no 4.024, de 20 de dezembro de 1961. Fixa as diretrizes e bases da educação nacional. Diário Oficial da União, Brasília, 27 dez. 1961. Disponível em: < http:/ /www. planalto.gov.br/ccivil_03/leis/14024.htm>. Acesso em: 13 maio 2015.

. Lei no 5.540 , de 28 de novembro de 1968. Fixa normas de organização e funcionamento do ensino superior e sua articulação com a escola média, e dá outras providências. Diário Oficial da União, Brasilia, 29 nov. 1968, Seção 1, p. 10369. Disponível em: <http://www2.camara.leg.br/legin/fed/lei/1960-1969/lei-5540-28-novembro-1968359201-publicacaooriginal-1-pl.html>. Acesso em: 13 maio 2015.

. Lei $\mathrm{n}^{\circ}$ 5.692, de 11 de agosto de 1971. Fixa diretrizes e bases para o ensino de $1^{\circ}$ e $2^{\circ}$ graus, e dá outras providências. Diário Oficial da União, Brasília, 12 ago. 1971. Disponível em: <http://www010.dataprev.gov.br/sislex/paginas/42/1971/5692.htm>. Acesso em: 13 maio 2015.

. Lei $\mathrm{n}^{\circ}$ 9.394, de 20 de dezembro de 1996. Estabelece as diretrizes e bases da educação nacional. Diário Oficial da União, Brasília, 23 dez. 1996. Disponível em: <http:/ /www.planalto.gov.br/ccivil_03/leis/19394.htm>. Acesso em: 13 maio 2015.

BRASIL. Conselho Federal de Educação. Parecer 295/62. Currículo mínimo para a licenciatura em matemática. Documenta, Brasília, n. 10, p. 85-87, 1962.

. Conselho Nacional de Educação. Parecer CNE/CES 1.302/2001. Diretrizes curriculares nacionais para os cursos de matemática, bacharelado e licenciatura. Diário Oficial da União, Brasília, 05 mar. 2002a, Seção 1, p. 15. Disponível em: < http://portal. mec.gov.br/cne/arquivos/pdf/CES13022.pdf >. Acesso em: 13 maio 2015.

. Parecer CNE/CP 9/2001. Diretrizes curriculares nacionais para a formação de professores da educação básica, em nível superior, curso de licenciatura, de graduação plena. Diário Oficial da União, Brasília, 18 jan. 2002b, Seção 1, p. 31. Disponível em: < http:/ / portal.mec.gov.br/cne/arquivos/pdf/009.pdf>. Acesso em: 13 maio 2015.

GATTI, B. A; NUNES, M. M. R. (Coord.). Formação de professores para o ensino fundamental: instituições formadoras e seus currículos. Relatório final: estudo dos cursos de licenciatura no Brasil: letras, matemática e ciências biológicas. São Paulo: Fundação Carlos Chagas, 2008. v. 2. Disponível em: < http://www.fvc.org.br/pdf/Formacao \%20de\%20 Professores\%20no\%20Brasil.pdf $>$. Acesso em: 13 maio 2015.

GHIRALDELLI JR., P. História da educação brasileira. 4. ed. São Paulo: Cortez, 2009.

HARGREAVES, A. O ensino na sociedade do conhecimento: educação na era da insegurança. Porto Alegre: Artmed, 2004. 
MARQUES, C. A.; DINIZ PEREIRA, J. E. Fóruns das licenciaturas em universidades brasileiras: construindo alternativas para a formação inicial de professores. Educação \& Sociedade, Campinas, n. 78, p. 171-183, 2002.

SUCUPIRA, N. A condição atual da universidade e a reforma universitária brasileira.

Brasília: MEC, 1972. Disponível em: <http://www.dominiopublico.gov.br/download/texto/ me002101.pdf>. Acesso em: 13 maio 2015.

ZICCARDI, L. R. N. O curso de matemática da Pontifícia Universidade Católica de

São Paulo: uma história de sua constituição/desenvolvimento/legitimação. 2009. 412 f. Tese (Doutorado em Educação Matemática) - Pontifícia Universidade Católica de São Paulo, São Paulo, 2009. 